Artigo Tecnológico

\title{
Eficiência das Ferrovias Especializadas em Transporte de Minério de Ferro e Pelotas
}

\section{The Efficiency of Railways Specialized in Transporting Iron Ore and Pellets}

\author{
Renata G. de Oliveira Fontan ${ }^{10}$ \\ Rodrigo Alvarenga Rosa ${ }^{1}$ (c) \\ Adonai José Lacruz*2,3
}

\section{RESUMO}

Objetivo: objetiva-se comparar a eficiência relativa das ferrovias especializadas em transporte de minério de ferro (MFe) e pelota (PLMFe), que fazem parte do patrimônio das empresas de mineração e usinas de pelotização considerando o cenário de 2016. Métodos: foi utilizada a técnica análise envoltória de dados (DEA), com aplicação do modelo de retornos constantes de escala (CCR) e orientaçáo à saída (output); o método multicritério combinatório inicial para escolha das variáveis de entrada e a regressão Tobit como estratégia de validação do modelo DEA. Resultados: das doze ferrovias avaliadas, três ferrovias foram identificadas como eficientes: Estrada de Ferro Carajás, Fortescue e Mount Newman. Conclusóes: o modelo aplicado foi considerado como um bom método para avaliar a eficiência das ferrovias especializadas em transporte de MFe e PLMFe, pois determinou a eficiência de cada ferrovia, sugerindo o aumento necessário na variável de saída ou ajustes nas variáveis de entrada para que as ferrovias atinjam a fronteira de eficiência. Com isso, as empresas podem utilizar os resultados deste estudo para guiar melhorias futuras para tornar suas ferrovias mais eficientes ou se manter na fronteira de eficiência.

Palavras-chave: ferrovias especializadas em minério de ferro e pelotas; análise envoltória de dados; eficiência do transporte ferroviário de carga.

\footnotetext{
* Autor Correspondente.

1. Universidade Federal do Espírito Santo, Programa de Pós-graduação em Engenharia Civil, Vitória, ES, Brasil. 2. Universidade Federal do Espírito Santo, Programa de Pós-graduação em Administração, Vitória, ES, Brasil.
} 3. Instituto Federal do Espírito Santo, Viana, ES, Brasil.

Como citar: Fontan, R. G. de O., Rosa, R. A., \& Lacruz, A. J. (2022). Eficiência das ferrovias especializadas em transporte de minério de ferro e pelotas. Revista de Administração Contemporânea, 26(1), e200284 https://doi.org/10.1590/1982-7849rac2022200284.por

A de revisores convidados ate a decisao:

\# de revisores convidados até a decisão:

\begin{tabular}{|c|c|c|c|c|c|c|c|c|c|}
\hline & 1 & 2 & 3 & 4 & 5 & 6 & 7 & 8 & 9 \\
\hline $1^{\circ}$ rodada & $x$ & 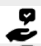 & & $\stackrel{8}{2}$ & & & & & \\
\hline $2^{a}$ rodada & 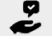 & & 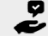 & & & & & & \\
\hline $3^{a}$ rodada & $x$ & , & & & & & & & \\
\hline
\end{tabular}

Classificação JEL: L7.

Objective: the objective is to compare the relative efficiency of the railways specialized in transporting iron ore (MFe) and pellets (PLMFe), which are part of the assets of mining companies and pellet plants considering the 2016 scenario. Methods: the methods used were the data envelopment analysis (DEA) technique, with the application of the output-oriented constant returns scale (CRS) model; the initial combinatorial multicriteria method for choosing the input variables; and Tobit regression as a validation strategy for the DEA model. Results: of the twelve railways evaluated, three railways were identified as efficient: Estrada de Ferro Carajás, Fortescue, and Mount Newman. Conclusions: the applied model was considered a good method to evaluate the efficiency of railways specialized in transporting MFe and PLMFe, as it determined the efficiency of each railway, suggesting the necessary increase in the output variable or adjustments in the input variables so that the railways reach the efficiency frontier. With that, companies can use the results of this study to guide future improvements to make their railways more efficient or maintain them on the frontier of efficiency.

Keywords: railways specialized in iron ore and pellets; data envelopment analysis; rail freight transport efficiency. 


\section{INTRODUÇÃO}

Este artigo tecnológico (Motta, 2017) é orientado aos praticantes e interessados no estudo da eficiência de ferrovias especializadas em transporte de minério de ferro $(\mathrm{MFe})$ e pelota (PLMFe) e/ou no método análise envoltória de dados (do inglês data envelopment analysis - DEA).

Objetivamente, avalia-se neste estudo a eficiência relativa das ferrovias especializadas em transporte de $\mathrm{MFe}$ e PLMFe, que fazem parte do patrimônio das empresas de mineraçáo e usinas de pelotização por meio da técnica DEA. Esclarece-se que os dados, coletados em 2018, refletem o cenário de 2016.

$\mathrm{O} \mathrm{MFe}$ é um mineral encontrado na natureza na forma de rochas, misturado a outros elementos. Por meio de processos de beneficiamento, o MFe é obtido em granularidade e quantidade de teor de ferro ideais para ser vendido às indústrias siderúrgicas. A PLMFe é um aglomerado de MFe em formato esférico, obtida em processo industrial, aproveitando os finos gerados durante a extração do minério, que antes eram descartados. Tanto o MFe quanto a PLMFe são fundamentais para a economia global por se tratarem de insumos para fabricação do aço.

Nesse mercado, as empresas, via de regra, decidem por estabelecer sua própria cadeia logística, necessitando, assim, construir a sua infraestrutura de transporte para escoar a produção de MFe e PLMFe. O meio de transporte que melhor atende ao volume movimentado por essas empresas é o ferroviário.

São consideradas como ferrovias especializadas no transporte de MFe e PLMFe aquelas que possuem esses produtos como predominantes em sua matriz de carga transportada. Essas duas cargas podem ser tratadas de forma semelhante por três motivos: (a) ambas possuem peso específico próximo de $2,22 \mathrm{ton} / \mathrm{m}^{3}$; (b) utilizam o mesmo tipo de vagão; e (c) suas operaçóes de carregamento, transporte e descarregamento são similares.

Algumas características que diferenciam esse tipo de ferrovia das demais é o peso da carga transportada por vagão, com alto valor de carga por eixo, exigindo mais de suas locomotivas e vagóes. Além disso, nessas ferrovias, via de regra, muitos trens circulam diariamente, acarretando um nível maior de degradaçáo na linha férrea, pelo aumento do tráfego de trens na via e pelo tamanho do trem, que é mais extenso, com mais locomotivas e vagóes em sua formação em relaçáo a trens de outros tipos de carga.

Além disso, por serem patrimônio das empresas mineradoras e/ou das usinas de pelotização, elas não cobram o frete pelo transporte e são vistas como centro de custos da operação da mina e/ou da usina de pelotizaçáo. No entanto, o modo ferroviário necessita de grandes investimentos e possui altos custos de operaçáo, o que impacta significativamente no valor final do produto.

Em linha com a estratégia de mercado e competitividade, as empresas buscam aumentar a eficiência do transporte ferroviário visando a reduzir seus custos.

Considerando que as ferrovias transportam produtos semelhantes, a comparação permitirá entender o motivo pelo qual uma ferrovia é mais eficiente que a outra. Nesse encadeamento, objetiva-se neste artigo avaliar as ferrovias especializadas no transporte de MFe e PLMFe utilizando a técnica DEA para mensurar e comparar sua eficiência, identificando quais ferrovias são consideradas eficientes e o quanto as demais estão distantes em relação a esta referência. Logo, tendo o desempenho relativo como resultado, é possível conhecer medidas que podem ser tomadas para tornar a ferrovia mais eficiente.

O modelo DEA escolhido para aplicação foi o retorno constante em escala ou CCR - em homenagem aos seus autores Charnes, Cooper e Rhodes (1978) -, com orientação à saída (output); ou seja, considera eficiência por uma função linear, caracterizada pela melhor relação de proporção das variáveis de saída com as variáveis de entrada de uma determinada unidade observada, também conhecida como decision-making unit (DMU). Assim, o objeto de estudo deste artigo são as 12 ferrovias no mundo especializadas no transporte de MFe e PLMFe e que fazem parte do patrimônio de grandes empresas mineradoras e/ou pelotizadoras, consideradas como DMUs.

Como variáveis de entrada, representando os insumos (inputs), foram adotados: número de vagóes em operação (VAG), carga por eixo (CGE) e quantidade de vagóes do trem tipo de maior predominância (TTP). Como variável de saída, representando o produto (output), foi adotado o indicador tonelada por quilômetro útil (TKU), que representa a tonelada útil transportada pela distância percorrida. Esclarece-se que para a seleção das variáveis foi utilizado o método multicritério combinatório inicial e que a regressão Tobit foi usada como estratégia de validação do modelo de eficiência.

Os dados do ano de 2016, coletados em 2018, refletem quatro dos cinco grandes eventos que alteraram a dinâmica do mercado, sendo eles: entrada do novo player Fortescue; retração do mercado chinês e forte queda dos preços do MFe; rompimento da barragem de rejeito da Samarco; e início da produção da mina S11D da Vale. De posse dos resultados de 2016, divulgados pelas empresas, foram levantados os dados das ferrovias.

Este artigo se justifica porque difere dos demais publicados sobre DEA e ferrovia, uma vez que trata da análise de ferrovias de transporte de MFe e PLMFe que fazem parte do patrimônio de empresas mineradoras e/ou 
usinas de pelotização $e$, portanto, não cobram frete para o transporte de MFe e PLMFe, sendo tratadas como centros de custos pelas referidas empresas. Também se diferenciam por operarem com trens mais longos, com maior quantidade de vagóes e com vagóes mais pesados (maior peso por eixo). Além disso, as empresas possuem autonomia na tomada de decisóes para aumentar a eficiência e reduzir custos.

Este artigo contribui para a prática gerencial ao apresentar a fronteira de eficiência e, consequentemente, as ferrovias eficientes na aplicação dos recursos, bem como as ações que as empresas podem tomar para melhorar seu índice de eficiência e, consequentemente, aumentar sua competitividade.

\section{CONTEXTO DA INVESTIGAÇÃO}

$\mathrm{O} \mathrm{MFe}$ e o PLMFe (pelota feita de aglomerado de finos de $\mathrm{MFe}$ gerados durante a extração do $\mathrm{MFe}$ ) são fundamentais para a economia global por se tratarem de insumos para fabricação do aço, com grande demanda pelas indústrias automotivas, de maquinários e construção civil.

Consulta realizada em 2020 no website Statista acerca do cenário de 2016 mostra que foram produzidos no mundo 2,34 bilhôes de toneladas de MFe, liderado pela Austrália com uma produção de aproximadamente 825 milhóes de toneladas, o que equivale a $34 \%$ do cenário global. Em segundo lugar no ranking está o Brasil, que produziu em 2016 por volta de 391 milhóes de toneladas, representando $16 \%$ da produçáo mundial, seguido pela China, com uma produçáo de 353 milhôes de toneladas, responsável por 14\% da produção mundial (Garside, 2020). Nos últimos anos, cinco grandes eventos alteraram a dinâmica do mercado de minério de ferro e interferiram na forma de operação das mineradoras/usinas de pelotização. Em 2014 surgiu a empresa Fortescue, um novo concorrente australiano com uma produção expressiva de 165 milhôes de toneladas ao ano (Mta) de MFe, assumindo um espaço no mercado que ocasionou perda de market share das concorrentes. Em 2015, com a redução da demanda por parte da China, o mercado reagiu com queda expressiva do preço do $\mathrm{MFe}$, o que provocou cancelamentos e/ou postergaçôes de vários projetos de expansão de minas de MFe. No final de 2015 ocorreu o rompimento da barragem de rejeitos da empresa brasileira Samarco, retirando por consequência um volume significativo de pelotas do mercado. Em 2016 iniciou a produção da mina S11D da empresa Vale, que possibilitou a oferta adicional de 90 milhóes de toneladas ao ano de MFe de altíssima qualidade. Além disso, no início de 2019 ocorreu o rompimento da barragem de rejeito da mineradora Vale, na cidade de Brumadinho, que ocasionou interdiçóes em várias operaçóes desta empresa, reduzindo a oferta de $\mathrm{MFe}$ e PLMFe e desequilibrando novamente o mercado. Diante de fatos que provocam constantes mudanças de avaliação do mercado e volatilidade no preço do MFe e do PLMFe, todas as empresas mineradoras e produtoras de pelotas buscaram formas de reduzir custos e aumentar a produtividade, com o objetivo de melhorar sua competitividade num mercado tão dinâmico.

Existem 12 ferrovias no mundo especializadas no transporte de MFe e PLMFe e que fazem parte do patrimônio de grandes empresas mineradoras e/ou pelotizadoras, sendo cinco anglo-australianas (uma da BHP Billiton, duas da Rio Tinto, uma da Fortescue e uma da Roy Hill), duas brasileiras, da Vale, duas canadenses (uma da Rio Tinto e uma da Arcelor Mittal), uma europeia, da LKAB, e duas africanas (uma da Arcelor Mittal e outra da SNIM).

Essa escolha foi feita pelo fato de essas empresas terem autonomia para implementar açóes que possam melhorar a performance do seu transporte ferroviário. Foram desconsideradas as ferrovias que são prestadoras de serviço, nas quais as mineradoras pagam tarifas para o transporte de sua produção e não possuem autonomia para modificaçóes operacionais; dentre estas, cita-se no Brasil a MRS Logística S/A.

Em um cenário competitivo, em busca por reduçáo de custo e ganho em produtividade, surgem os seguintes questionamentos: Quais ferrovias especializadas no transporte de MFe e PLMFe no cenário global foram eficientes na aplicação dos recursos no ano de 2016? Quais são os pontos de ineficiência que merecem atenção?

Esses questionamentos endereçam o objetivo aplicado de demonstrar a aplicação da metodologia DEA para lidar com essa problematização.

\section{ANÁLISE ENVOLTÓRIA DE DADOS E EFICIÊNCIA DE FERROVIAS}

O método DEA foi inicialmente desenvolvido por Charnes et al. (1978) e utiliza a programação linear para calcular a eficiência de unidades observadas, denominadas de decision-making units (DMUs). A DMU pode ser definida como uma empresa ou uma divisão organizacional da empresa na qual sua eficiência é avaliada. $O$ objetivo da aplicaçáo da metodologia DEA é comparar as DMUs escolhidas que realizam atividades semelhantes. A partir disso, verificam-se quais DMUs estão na fronteira de eficiência, com índice de eficiência igual a um. As ferrovias que possuem índice de eficiência abaixo de um não são consideradas como eficientes.

Existem dois modelos que representam a metodologia DEA: o de Charnes, Cooper e Rhodes (CCR) e o de Banker, Charnes e Cooper (BCC). O CCR calcula a eficiência por 
uma função linear, caracterizada pela melhor relação de proporção dos outputs com os inputs de uma determinada DMU. Uma característica do CCR diz respeito à escolha da orientação, seja ela entrada, seja de saída, que não influencia o valor da eficiência, pois esse modelo trabalha com a variação proporcional entre as entradas e saídas. Sendo assim, a escolha é feita com base no objetivo que se deseja alcançar: reduzir a utilização dos insumos (inputs) ou aumentar a produção (output) (Cinca, Molinero, \& Callén, 2016).

O BCC foi proposto depois do CCR e considera rendimentos de escala, substituindo a teoria da proporcionalidade entre inputs e outputs pela teoria da convexidade. O maior diferencial do BCC foi a introdução do conceito de retorno variável de escala, com o acréscimo da variável que representa o fator de escala (Reis, Sacramento, Mello, \& Meza, 2017). A principal característica do modelo BCC é que a fronteira de eficiência é limitada às combinaçôes convexas dos planos de produção observados, enquanto no CCR a fronteira de eficiência é uma reta com inclinação de 45 graus (Bogetoft \& Otto, 2011).

Além de mensurar a eficiência, o método DEA oferece dados sobre a ineficiência mostrando quais variáveis de entrada ou saída foram utilizadas de forma insatisfatória e quais apresentam folgas que poderiam ser eliminadas (Lin \& Tseng, 2007). O modelo DEA poderá ter duas diferentes orientaçóes que indicaráo a maneira pela qual um DMU atingirá a fronteira de eficiência: (a) orientação à entrada ou (b) orientação à saída. A primeira busca responder qual é a quantidade possível de reduçáo proporcional de insumos (inputs) sem alterar as quantidades produzidas (outputs). A segunda aponta qual é a quantidade possível de aumento proporcional de saída (output) sem mudar as quantidades de entrada (input), ou seja, busca a obtençáo do melhor resultado pela aplicação de um determinado nível de recurso (Caldas, Gabriele, Carvalhal, \& Ramos, 2012).

A seguir, apresenta-se uma breve revisão da literatura, a partir de busca das seguintes palavras-chave: benchmarking, ferrovia, railway, railroad, eficiência, efficiency DEA, data envelopment analysis, transporte de carga e freight, nos sites: Periódicos Capes, Science Direct, Scopus e Google Scholar.

Yu (2008) avaliou 40 ferrovias europeias e apurou três medidas de desempenho para as ferrovias: eficiência técnica, eficácia do serviço e eficácia técnica, de modo a ajudar as empresas a melhorar o desempenho de suas ferrovias. Asmild, Holvad, Hougaard e Kronborg (2009) estimaram separadamente a ineficiência em cada parcela de custo da ferrovia (infraestrutura, equipamentos, manutenção, pessoal, etc.), investigando assim o impacto das reformas ferroviárias europeias nos custos da operação.
Cantos, Pastor e Serrano (2012) avaliaram, utilizando DEA, 23 ferrovias europeias no período de 2001 a 2008 para estimar a evolução dos níveis de eficiência após processo de regulamentação e reestruturação do transporte ferroviário na Europa. Os resultados mostram que a introduçáo da concorrência nos setores de transporte de carga e passageiros teve um impacto positivo tanto na eficiência quanto na produtividade.

Kutlar, Kabasakal e Sarikaya (2013) mediram o desempenho das empresas ferroviárias de transporte de carga e passageiros em todo o mundo, no período de 2000 a 2009. Eles utilizaram DEA CCR e BCC. Eles ressaltaram que o DEA permite avaliar um grande número de variáveis (entrada e/ou saída) simultaneamente, sendo útil para aplicaçóes reais. Pereira, Rosa e Lunkes (2015) avaliaram, utilizando DEA, a eficiência das empresas concessionárias ferroviárias do Brasil no período de 2009 a 2013, com viés financeiro, avaliando gastos como input e receita como output. Das onze ferrovias analisadas, quatro apresentaram eficiência máxima nos cinco anos analisados.

Sharma, Debnath, Oloruntoba e Sharma (2016) consideram que a escolha por $\mathrm{DEA}$ em relação à metodologia stochastic frontier analysis (SFA) foi feita porque o SFA assume uma forma funcional preconcebida da fronteira de produção, ao passo que a abordagem DEA usa programação linear para construir a fronteira de produçáo, que envolve todas as unidades de medida (DMU). Reis, Sacramento, Mello e Meza (2017) utilizaram DEA BCC output para calcular a eficiência de doze ferrovias brasileiras de transporte de carga. Os resultados apontaram cinco ferrovias eficientes. Os autores não chegaram a uma conclusão sobre os motivos que influenciaram as ferrovias a alcançarem a eficiência.

Marchetti e Wanke (2017) avaliaram a eficiência de doze ferrovias brasileiras entre 2010 e 2014, quando foram introduzidos novos regulamentos competitivos no Brasil. Foram utilizados os modelos DEA BCC e CCR para identificação da eficiência. Os autores constataram que o compartilhamento de infraestrutura com mais de um operador não influenciou o desempenho das DMU.

Zhou e $\mathrm{Hu}$ (2017) utilizaram DEA BCC em dois estágios (produção e serviço) para calcular o desempenho de sustentabilidade geral e subestágio do transporte ferroviário na China de 2002 a 2013, a partir dos aspectos de economia, meio ambiente e sociedade. Wanke, Chen, Liu, Antunes e Azad (2018) investigaram os impulsionadores do desempenho ferroviário em países asiáticos tendo em vista que as publicaçóes focam mais em medição da eficiência e pouco discutem açóes para possíveis melhorias.

Silva, Oliveira e Marinov (2020) avaliaram o impacto da fusão vertical que formou a empresa RUMO-ALL sobre a eficiência do transporte de cargas em quatro ferroviárias 
brasileiras. Foram considerados os dados de 2006 a 2018, com a utilização do DEA CCR input. Os autores comentam que as principais questóes operacionais que podem limitar ou aumentar a produtividade das ferrovias são: tamanho do trem, tempo de expedição dos trens, peso carregado em cada vagáo, disponibilidade operacional das locomotivas e vagóes e velocidade da via. O resultado apontou mudança de eficiência significativa em duas ferrovias, sugerindo ter ocorrido uma priorização do transporte de carga pesada.

Nesta revisão da literatura não foi encontrada nenhuma publicação que tratasse somente de ferrovias proprietárias de empresas mineradoras ou usinas de MFe e PLMFe. Estas diferem das demais sobretudo por não cobrarem frete $\mathrm{e}$ terem características operacionais distintas dos outros tipos de ferrovias, tanto assim que são denominadas ferrovias heavy haul, por seus trens serem mais longos, com vagóes com maior tonelada por eixo.

O modelo utilizado para este artigo foi DEA CCR output. A orientação foi definida em função da escolha de reduzir os insumos (variáveis de entrada) sem alterar as quantidades produzidas (variáveis de saída) ou aumentar a quantidade produzida (variáveis de saída) com os insumos existentes (variáveis de entrada). Para este estudo, a orientação à entrada (input) foi avaliada como inviável pelo fato de minimizar recursos da ferrovia, o que leva à perda de escala no transporte ou à redução da capacidade dos ativos, podendo deixar a empresa vulnerável em caso de mudança para maior demanda no mercado de MFe e PLMFe. Essas medidas na ferrovia podem acarretar perda de competitividade caso o tempo de resposta da empresa seja demorado, perdendo espaço para o concorrente. Por esses motivos, faz mais sentido trabalhar com a orientação à saída (output), ou seja, aumentar o total de MFe e de PLMFe transportados pela ferrovia.

Tendo em vista o cenário estudado, que é um segmento de negócio mais restrito, e considerando as particularidades da ferrovia, definiu-se o modelo CCR como o mais adequado para resolver o problema proposto. $\mathrm{O}$ modelo CCR trabalha com a relação de proporcionalidade entre inputs e outputs, que se aplica melhor na avaliação da aplicação dos recursos (VAG, CGE e TTP) na obtenção do volume movimentado pela distância percorrida (TKU). No entanto, esses resultados estáo condicionados ao conjunto de valores das ferrovias apresentadas, e se alguma variável alterar-se ou houver modificaçóes na quantidade de DMU (inclusão ou exclusão), o resultado será outro, por se tratar de uma eficiência relativa.

\section{Aplicação da análise envoltória de dados}

Neste artigo, foi utilizado o método DEA CCR orientado à saída. O modelo CCR é apresentado no modelo a seguir, sendo a sua função objetivo apresentada na Equação 1, onde $E_{f f 0}$ é a eficiência da $\mathrm{DMU}_{0}$ em análise; $x_{i 0}$ : input $i \mathrm{daDMU} ; y_{j 0}$ : output da $\mathrm{DMU}_{0} ; x_{i k}$ : input $i \mathrm{da}$ $\operatorname{DMU} k, k=1, \ldots, n ; y_{j k}$ output $j$ da DMU $k, k=1, \ldots, n ; v_{i}$ : pesos do input $i, i=1, \ldots, r ; u_{j}$ : pesos do output $j, j=1, \ldots, s$; $\mathrm{u}^{*}$ : fator de escala.

Função objetivo:

Maximizar $E_{f f 0}=\sum_{j=1}^{s} u_{j} y_{j 0}$

Sujeito a:

$\sum_{i=1}^{r} v_{i} x_{i 0}=1$

$\sum_{j=1}^{s} u_{j} y_{j k}-\sum_{i=1}^{r} v_{i} x_{i k} \leq 0 \quad \forall k=1, \ldots, n$

$u_{j}, v_{i} \geq 0$

$$
\forall i=1, \ldots, r, j=1, \ldots, s
$$

$u * \in R$

O objetivo do CCR é determinar os pesos ótimos $u_{j}$ (variável de saída) e $v_{i}$ (variável de entrada). Se a eficiência $E_{f f 0}$ for igual a um, isso significa que a DMU é eficiente. Se o resultado for menor que um ou igual a zero, a DMU náo é considerada como eficiente.

O modelo DEA CCR baseia-se na hipótese de retornos constantes de escala, em que o crescimento do insumo (input) produzirá proporcional crescimento de produçáo (output), sendo a medição da eficiência do DEA CCR conhecida como a eficiência técnica (Marchetti \& Wanke, 2017).

As DMUs neste estudo são as ferrovias especializadas em transporte de MFe e PLMFe, que fazem parte do patrimônio das empresas (mineradoras e/ou usinas de pelotizaçáo). Doze ferrovias foram escolhidas, sendo duas brasileiras, duas canadenses, cinco australianas, uma liberiana, uma sueca e uma mauritana, conforme apresentado na Tabela 1. Foram desconsideradas as ferrovias prestadoras de serviço, caso em que as mineradoras pagam tarifas para o transporte de sua produção e não possuem autonomia para modificaçóes operacionais; dentre estas, cita-se no Brasil a MRS Logística S/A.

Posteriormente, foi realizado o levantamento das possíveis variáveis (input e output) a serem utilizadas. Com base no levantamento dos estudos apresentados no referencial teórico e consultas aos especialistas ferroviários, na Figura 1 são identificadas as variáveis mais relevantes utilizadas na comparação da eficiência entre ferrovias especializadas no transporte de MFe e PLMFe. 
Tabela 1. Ferrovias definidas como DMU.

\begin{tabular}{|c|c|c|c|c|}
\hline DMU & Ferrovia & Empresa & País & Carga \\
\hline 1 & Estrada de Ferro Vitória Minas (EFVM) & Vale & Brasil & $\mathrm{MFe}+\mathrm{PLMFe}$ \\
\hline 2 & Estrada de Ferro Carajás (EFC) & Vale & Brasil & $\mathrm{MFe}$ \\
\hline 3 & Mount Newman Railway (NEWM) & $\mathrm{BHP}$ & Austrália & $\mathrm{MFe}$ \\
\hline 4 & Hamersley Railway (RTHA) & Rio Tinto & Austrália & $\mathrm{MFe}$ \\
\hline 5 & Robe River (RTRR) & Rio Tinto & Austrália & $\mathrm{MFe}$ \\
\hline 6 & Fortescue Railway (FMG) & Fortescue & Austrália & $\mathrm{MFe}$ \\
\hline 7 & Roy Hill Railway (RHILL) & Roy Hill & Austrália & $\mathrm{MFe}$ \\
\hline 8 & QNS \& L (QNSL) & IOC & Canadá & PLMFe \\
\hline 9 & Cartier (CART) & Arcelor Mittal & Canadá & $\mathrm{MFe}+\mathrm{PLMFe}$ \\
\hline 10 & Yekepa-Buchanan Line (AML) & Arcelor Mittal & Libéria & $\mathrm{MFe}$ \\
\hline 11 & Iron Ore Line (IOL) & LKAB & Suécia & $\mathrm{MFe}+\mathrm{PLMFe}$ \\
\hline 12 & Mauritania Railway (MAUR) & SNIM & Mauritânia & $\mathrm{MFe}$ \\
\hline
\end{tabular}

Nota. Fonte: Elaborado pelos autores.

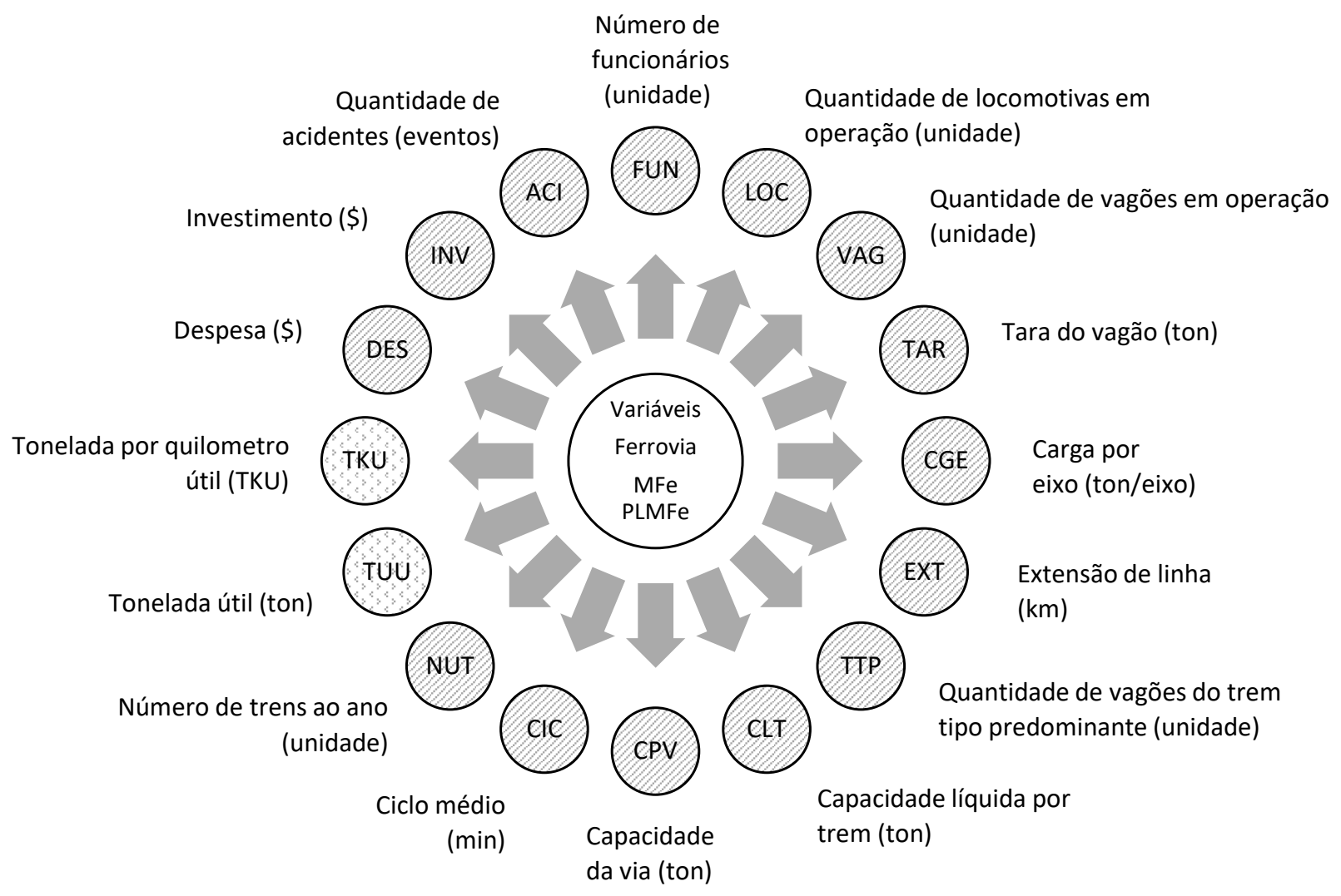

LEGENDA: $\bigcirc$ Variável de entrada $\bigcirc$ Variável de saída

Figura 1. Variáveis utilizadas para comparação entre ferrovias. 
Neste artigo, a orientação à entrada (input) foi avaliada como inviável pelo fato de minimizar recursos da ferrovia, o que leva à perda de escala no transporte ou à redução da capacidade da ferrovia. Isso pode deixar a empresa vulnerável em caso de aumento mundial da demanda de MFe e PLMFe, impossibilitando-a de responder rapidamente a esse aumento de demanda. Por esses motivos, faz mais sentido trabalhar com a orientação à saída (output), ou seja, aumentar o total de MFe e de PLMFe transportados pela ferrovia.

A maior dificuldade no levantamento dos dados foi a obtenção dos dados das ferrovias, pois são empresas privadas que divulgam resultados financeiros, mas não detalham as informaçôes técnicas de suas operaçôes. Os dados coletados são referentes ao ano de 2016 e as principais fontes para obtenção das informaçôes foram os relatórios institucionais das empresas proprietárias das ferrovias escolhidas como DMU e informaçóes dos órgãos regulamentadores do transporte ferroviário.

Nas pesquisas, foram obtidos os valores das variáveis: extensão de linha (EXT), que corresponde ao comprimento da ferrovia, que inicia na mina/usina e termina no porto ou em um ponto de descarga; quantidade de vagóes em operação (VAG); quantidade de locomotivas em operação (LOC); quantidade de vagóes do trem tipo de maior predominância (TTP); carga por eixo do vagão (CGE), que é a quantidade de MFe e/ou PLMFe transportada por cada rodeiro (eixo), considerando que os vagóes avaliados possuem quatro rodeiros. Para encontrar a tara do vagáo (TAR), foi necessário pesquisar qual é o tipo de vagão utilizado por cada empresa e o seu peso quando está vazio. A capacidade líquida por trem (CLT) é obtida por meio de cálculo, com a multiplicação do valor da carga por eixo (CGE) por quatro (cada vagão possui quatro rodeiros ou eixos) e a subtração do valor da tara do vagão (TAR). Em seguida, o valor é multiplicado pela quantidade de vagóes existentes no trem tipo de maior predominância (TTP) de cada empresa. As demais variáveis foram: número de trens (NUT), composto por locomotivas e vagóes carregados com MFe e PLMFe, que percorreram a extensão da ferrovia ao longo de um ano; volume movimentado de MFe e PLMFe em toneladas (TUU); tonelada por quilômetro útil (TKU), que representa a tonelada útil transportada multiplicada pela distância percorrida, em unidade ton.km. Com os dados coletados, foi elaborada a base de dados da Tabela 2 .

Tabela 2. Base de dados das DMUs.

\begin{tabular}{|c|c|c|c|c|c|c|c|c|c|c|}
\hline DMU & $\mathrm{EXT}^{1}$ & $\mathrm{VAG}^{2}$ & $\mathrm{LOC}^{2}$ & $\mathrm{TTP}^{3}$ & $\mathrm{CGE}^{4}$ & TAR $^{5}$ & CLT $^{5}$ & $\mathrm{NUT}^{2}$ & $\mathrm{TUU}^{5}$ & $\mathrm{TKU}^{6}$ \\
\hline EFVM & 895 & 11.925 & 325 & 252 & 27,5 & 18 & 23.310 & 4.406 & 103 & 91.917 \\
\hline EFC & 997 & 18.135 & 289 & 330 & 32,5 & 20 & 36.300 & 4.080 & 148 & 147.656 \\
\hline NEWM & 426 & 4.000 & 178 & 268 & 37,5 & 20 & 34.840 & 6.359 & 222 & 94.382 \\
\hline RTHA & 328 & 6.971 & 116 & 236 & 40,0 & 21 & 32.922 & 7.146 & 235 & 77.161 \\
\hline RTRR & 242 & 4.529 & 75 & 167 & 40,0 & 21 & 23.297 & 1.520 & 35 & 8.570 \\
\hline FMG & 620 & 4.600 & 53 & 250 & 42,0 & 20 & 37.000 & 4.676 & 173 & 107.260 \\
\hline RHILL & 344 & 1.196 & 21 & 232 & 45,0 & 22 & 36.749 & 599 & 22 & 7.568 \\
\hline QNSL & 418 & 1.000 & 20 & 265 & 36,0 & 20 & 32.860 & 554 & 18 & 7.608 \\
\hline CART & 420 & 1.340 & 30 & 200 & 30,0 & 18 & 20.400 & 1.225 & 25 & 10.500 \\
\hline AML & 243 & 195 & 4 & 70 & 30,0 & 18 & 7.140 & 294 & 2 & 510 \\
\hline IOL & 390 & 1.100 & 17 & 68 & 32,5 & 21 & 7.398 & 3.636 & 27 & 10.491 \\
\hline MAUR & 704 & 1.200 & 31 & 210 & 30,0 & 20 & 21.000 & 790 & 17 & 11.686 \\
\hline
\end{tabular}

Nota. Fonte: Elaborado pelos autores. Unidades de medida: ${ }^{1}$ quilômetro $(\mathrm{km}) ;{ }^{2}$ unidade; ${ }^{3}$ quantidade de vagóes por trem; ${ }^{4}$ toneladas por eixo (ton/eixo); ${ }^{5}$ tonelada (ton); ${ }^{6}$ milhôes de toneladas por quilômetro (milhóes ton.km).

Ao conhecer a relação de causalidade entre as variáveis, é possível explicar como uma determinada causa implica um efeito específico. Com o auxílio de especialistas da área em conjunto com a Tabela 2, foi montada a Figura 2, que demonstra essa relação por meio das setas e, adicionalmente, é apresentado o coeficiente de correlação entre as variáveis abordadas (calculado usando o software Stata). Com base na Figura 2, é possível verificar a relação de causalidade entre as variáveis levantadas para mensurar a eficiência das ferrovias especializadas no transporte de MFe e PLMFe e que são patrimônio das empresas mineradoras e usinas de pelotização. 


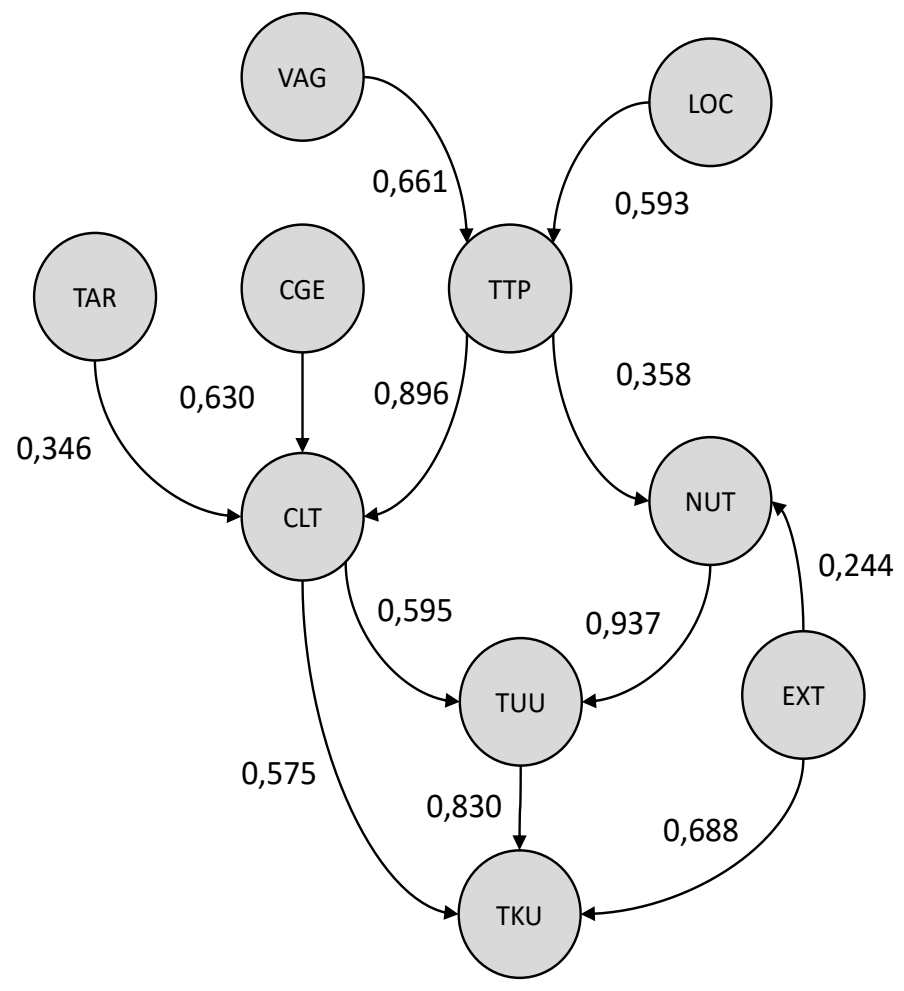

Figura 2. Relação de causalidade entre as variáveis.

Acrescenta-se que pela gradação de Miles e Shevlin (2001), valores entre 0,10 e $0,29,0,30$ e 0,49 e maiores que 0,50 são considerados baixos, moderados e elevados, respectivamente.

O método DEA possui uma limitação relacionada à quantidade de variáveis: se forem utilizadas muitas variáveis em relação à quantidade de DMUs, haverá uma tendência de muitas destas ficarem próximas à eficiência máxima, perdendo assim o poder discricionário. Esse problema pode ser evitado ao restringir-se a quantidade de variáveis utilizadas no modelo. Como este estudo possui uma quantidade limitada de DMUs, que representam um segmento de negócio específico, foi adotada a restrição da Golden Rule (Banker, Charnes, Cooper, Swarts, \& Thomas, 1989), apresentada na Equaçáo 6, na qual $\mathrm{n}=$ número de observaçóes da amostra, $\mathrm{p}=$ inputs e $\mathrm{q}=$ outputs.

$\mathrm{n} \geq \operatorname{MAX}_{\{p \times q, 3(p+q)\}}$

Registra-se que a abordagem DEA bootstrap (ou smoothed bootstrap), desenvolvida por Simar e Wilson (1998), corrige o viés ascendente do método DEA quando o tamanho da amostra é inadequado para o número de entradas e saídas (i.e., Golden Rule). Porém, como adverte Chernick (2008), o tamanho da amostra deve ser de no
Legenda:

\#,\#\#\# = Coefição de causalidade
VAG $=$ Quantidade de vagões em operação
LOC $=$ Quãontidade de locomotivas em operação
TAR $=$ Tara do vagão
CGE $=$ Carga por eixo do vagão
TTP $=$ Quantidade de vagões do trem tipo predominante
CLT $=$ Capacidade líquida por trem
NUT $=$ Número de trens ao ano
TUU $=$ Tonelada útil
EXT $=$ Extensão de linha
TKU $=$ Tonelada por quilometro útil

mínimo 50 observaçôes para serem estimadas pontuações confiáveis consistentes usando o DEA bootstrap.

A seleção das variáveis é a parte mais crítica do desenvolvimento do modelo DEA, pois a escolha de diferentes conjuntos de variáveis pode levar a diferentes análises (Merkert, Smith, \& Nash, 2010). Em muitos trabalhos, essa seleção de variáveis é feita de acordo com a opiniáo de especialistas, o que pode levar a um resultado tendencioso. Dessa forma, para evitar esse tipo de problema, adotou-se o método multicritério combinatório inicial para selecionar as variáveis, pois ele independe da opiniáo do decisor (Senra, Nanci, Mello, \& Meza, 2007). Esse método é uma variação do método multicritério de seleção de variáveis (Mello, Gomes, Meza, \& Lins, 2004), caracterizado por uma boa ordenação das DMUs, sendo imparcial na escolha das variáveis por meio de uma ponderação entre a capacidade discriminatória e a eficiência média do modelo.

No entanto, antes de iniciar o método de seleção é fundamental uma análise prévia de possíveis variáveis pelos especialistas e/ou decisores, com o objetivo de avaliar quais variáveis contribuem com o real propósito da análise, que contribuem com a eficiência no transporte de MFe e PLMFe. Com o auxílio de seis profissionais da área de operação de empresas ferroviárias, foi realizada uma seleçáo prévia das variáveis a serem associadas ao output TKU, sendo elas: VAG, LOC, CLT, TTP e CGE. Com essa pré-seleção, foram 
formados os pares input-output: VAG-TKU, LOC-TKU, CLT-TKU, CGE-TKU e TTP-TKU.

O método multicritério combinatório inicial pondera os resultados em funçáo de dois critérios: (a) a maximização da eficiência e (b) a minimização da discriminação, ambos calculados pela Equação 1. O ajuste à fronteira é medido por meio da eficiência média, que depois da normalização é denominada variável $\mathrm{S}_{\mathrm{EF}}$, assumindo o valor 10 para eficiência máxima e zero para eficiência mínima. A minimizaçáo da discriminação é medida pela quantidade de DMUs que atingiram a eficiência, que após a normalização é denominada variável $\mathrm{S}_{\mathrm{DIS}}$, a qual assume o valor 10 para o menor número de DMUs na fronteira e zero para o maior número de DMUs que atingiram a fronteira. O parâmetro $\omega$ permite atribuir maior ou menor importância a cada um dos critérios conforme a necessidade da análise. No entanto, como este estudo representa um segmento específico do negócio de MFe e PLMFe, os especialistas técnicos concluíram que é mais relevante dar mais notoriedade à eficiência do que à quantidade de DMUs na fronteira de eficiência, sendo atribuído o valor de 0,6 para $\omega$. O cálculo inicial é feito para cada par input-output e aquele que possuir o maior valor de $S$, obtido pela Equação 7, é incorporado ao modelo.

$S=\omega * S_{E F}+(1-\omega) * S_{D I S}$

Na Tabela 3, observa-se que na primeira rodada do modelo CCR output foi o par TTP-TKU que obteve o maior valor de $S$, alcançando valor igual a 1,00 e, por isso, foi o primeiro par input-output escolhido.

Tabela 3. Primeira rodada do método multicritério combinatório inicial para DEA CCR.

\begin{tabular}{|c|c|c|c|c|c|}
\hline \multirow[b]{2}{*}{ Input } & \multicolumn{5}{|c|}{ Índice de eficiência CCR output } \\
\hline & VAG & CLT & CGE & LOC & TTP \\
\hline Output & TKU & TKU & TKU & TKU & TKU \\
\hline EFVM & 0,3267 & 0,9694 & 0,7357 & 0,1397 & 0,8152 \\
\hline EFC & 0,3451 & 1,0000 & 1,0000 & 0,2525 & 1,0000 \\
\hline NEWM & 1,0000 & 0,6660 & 0,5540 & 0,2620 & 0,7871 \\
\hline RTRR & 0,0802 & 0,0904 & 0,0472 & 0,0563 & 0,1147 \\
\hline RTHA & 0,4691 & 0,5762 & 0,4246 & 0,3293 & 0,7307 \\
\hline FMG & 0,9882 & 0,7127 & 0,5621 & 1,0000 & 0,9589 \\
\hline RHILL & 0,2682 & 0,0506 & 0,0370 & 0,1781 & 0,0729 \\
\hline QNSL & 0,3224 & 0,0569 & 0,0465 & 0,1880 & 0,0642 \\
\hline CART & 0,3321 & 0,1265 & 0,0770 & 0,1729 & 0,1173 \\
\hline AML & 0,1109 & 0,0176 & 0,0037 & 0,0630 & 0,0163 \\
\hline IOL & 0,4042 & 0,3486 & 0,0711 & 0,3049 & 0,3448 \\
\hline MAUR & 0,4127 & 0,1368 & 0,0857 & 0,1863 & 0,1244 \\
\hline Eficiência média: & 0,4216 & 0,3960 & 0,3037 & 0,2611 & 0,4289 \\
\hline $\begin{array}{l}\text { Qtd. DMU na } \\
\text { fronteira: }\end{array}$ & 1 & 1 & 1 & 1 & 1 \\
\hline $\mathrm{S}_{\mathrm{EF}}:$ & 0,95 & 0,90 & 0,30 & 0,00 & 1,00 \\
\hline$S_{\text {DIS }}:$ & 1,00 & 1,00 & 1,00 & 1,00 & 1,00 \\
\hline$\omega:$ & 0,60 & 0,60 & 0,60 & 0,60 & 0,60 \\
\hline$S:$ & 0,97 & 0,94 & 0,58 & 0,40 & 1,00 \\
\hline
\end{tabular}

Nota. Fonte: Elaborado pelos autores.

$\mathrm{Na}$ segunda rodada do modelo CCR output, as variáveis de entrada VAG, CGE e LOC foram incorporadas separadamente ao par TTP-TKU. A variável CLT foi excluída por ter forte correlação $(0,896)$ com a variável TTP, que foi selecionada na primeira rodada. Utilizando a
Equação 7 para as combinações feitas, a variável VAG foi a segunda variável de entrada selecionada por ter alcançado o maior valor de $S$, de 0,60 .

As rodadas são repetidas até ser atendida a restrição da quantidade de variáveis por modelo do método DEA. Como 
este estudo adotou a restrição da Golden Rule (Banker et al., 1989), a quantidade de variáveis a serem selecionadas estará limitada a quatro, o que representa três rodadas. $\mathrm{Na}$ terceira e última rodada, a variável LOC foi excluída por ter forte correlação $(0,906)$ com a variável VAG, que foi selecionada na segunda rodada, restando assim somente a variável CGE para ser selecionada.

Como conclusão do método multicritério combinatório inicial, para o modelo CCR output foram selecionadas três variáveis como entrada (VAG, CGE e TTP) e uma variável de saída (TKU).

\section{ANÁLISE DOS RESULTADOS}

Esta seção aborda os resultados e as análises da comparação das ferrovias especializadas em transporte de MFe e PLMFe, caracterizada pela aplicação do método DEA. Conforme visto na seção "Análise envoltória de dados e eficiência de ferrovias", foram adotadas três variáveis de entrada (VAG, CGE e TTP) e uma variável de saída (TKU). Utilizou-se o software Frontier Analyst para rodar o modelo DEA.

As eficiências foram calculadas e aquelas que alcançaram índice de eficiência igual a um foram consideradas como DMUs (ferrovias) eficientes. Pelo modelo CCR output, existem três ferrovias com índice de eficiência igual a um, sendo elas: EFC da Vale, NEWM da BHP e FMG da Fortescue. Pelo modelo BCC output, sete ferrovias apresentam índice de eficiência igual a um, sendo elas: EFVM e EFC da Vale, NEWM da BHP, FMG da Fortescue, AML da Arcelor Mittal, IOL da LKAB e MAUR da Mauritânia. As demais possuem índice de eficiência abaixo de um e não são consideradas eficientes.

Considerando as particularidades da ferrovia, o modelo CCR mostrou-se mais adequado por trabalhar com a relação de proporcionalidade entre os inputs e os outputs, que se aplica melhor na avaliação da aplicação dos recursos (VAG, CGE e TTP) na obtenção do volume movimentado pela distância percorrida (TKU).

Por fim, como estratégia de validação do modelo DEA, foi processada a regressão Tobit, que trata de variáveis dependentes censuradas; ou seja, que não estão livremente distribuídas entre $-\infty \mathrm{e}+\infty$ (Gujarati, 2000), como o índice de eficiência que emerge de modelos DEA.

Para tanto, foram utilizadas como variáveis independentes as mesmas variáveis do modelo DEA desenvolvido (VAG, TTP, CGE e TKU) e como variável dependente a eficiência revelada na aplicação da DEA. Adicionalmente, foi utilizado procedimento de reamostragem bootstrap (1.000 replicaçóes). Explica-se que foi feito espelhamento do banco de dados, por estar limitado a 12 observaçóes, e que foi utilizado o software Stata.

Os resultados permitem validar o modelo DEA aplicado, pois os coeficientes de todas as variáveis se mostraram estatisticamente significantes ( $p$-value $<0,05$ ) tanto nos dados originais (espelhados) quanto no procedimento bootstrap.

A Figura 3 apresenta graficamente os índices de eficiência calculados utilizando o modelo CCR output para as doze ferrovias avaliadas, onde foi possível identificar três ferrovias eficientes, sendo elas: Estrada de Ferro Carajás (EFC), Fortescue (FMG) e Mount Newman (NEWM).

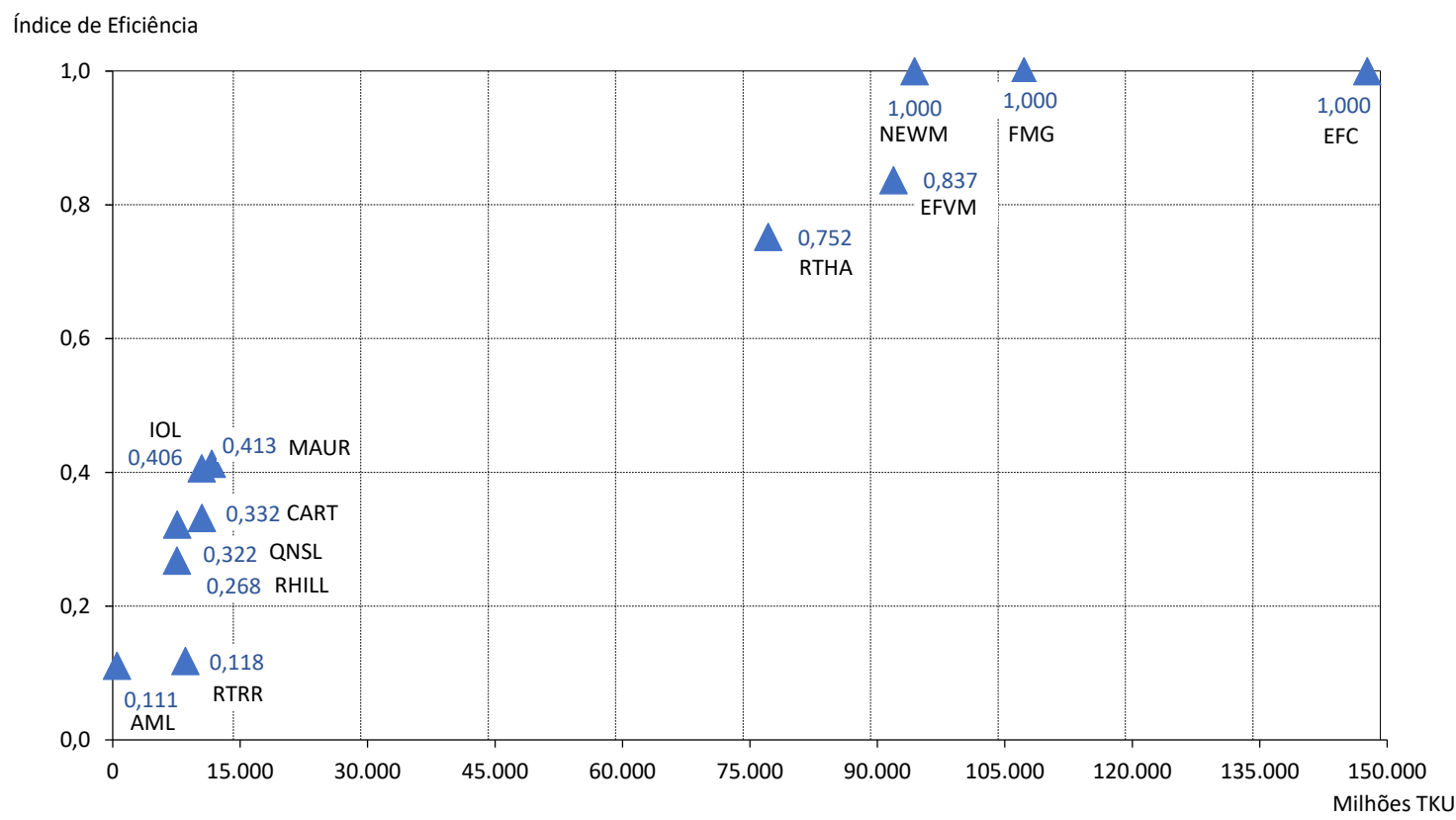

Figura 3. Resultado gráfico do modelo CCR output. 
Os alvos para a variável de saída TKU das DMUs que não atingiram o índice de eficiência igual a um auxiliam as empresas a avaliar medidas que podem ser tomadas no transporte ferroviário para melhorar a eficiência. Além disso, o resultado apresenta as DMUs que possuem folgas em uma ou mais variáveis de entrada. Para a variável VAG, nenhuma DMU apresentou folga, o que demonstra que essa variável de entrada está adequada em relação à variável de saída TKU. Para as variáveis TTP e CGE, o modelo indicou adequaçóes.

A Tabela 4 apresenta o alvo e a folga das variáveis de entrada TTP e CGE para cada DMU. Para a variável TTP, seis DMU apresentam folga na quantidade de vagóes que fazem parte do trem tipo de maior predominância na ferrovia. Na EFVM o ajuste é menor, com a proposta de redução de cinco vagões. Nas demais ferrovias, a proposta de redução é mais significativa, variando de 57 a 198 vagóes na composição de um trem. Reduzir a quantidade de vagóes do trem tipo de maior predominância (TTP) não aparenta ser uma boa opção, tendo em vista uma perda de escala no transporte em ferrovias já planejadas para o trem tipo existente.

Para a variável de entrada CGE, oito DMUs apresentam folga, demandando ajustes que variam desde 5,3 até 33,8 ton/eixo. A redução da carga por eixo (CGE) pode ser alcançada com a diminuição da quantidade de produto transportado por vagão, mas não faz sentido transportar vários vagóes sem utilizar sua capacidade máxima.

Tabela 4. Alvo e folga das variáveis TTP, CGE e TKU.

\begin{tabular}{ccccccccccc}
\hline \multirow{2}{*}{ DMU } & \multirow{2}{*}{$\begin{array}{c}\text { Índice } \\
\text { Eficiência }\end{array}$} & \multicolumn{3}{c}{ Valores observados } & \multicolumn{3}{c}{ Valores-alvo } & \multicolumn{2}{c}{ Valores de folga } & Incremento \\
\cline { 3 - 11 } & & TTP $^{1}$ & CGE $^{2}$ & TKU $^{3}$ & TTP $^{1}$ & CGE $^{2}$ & TKU $^{3}$ & TTP $^{1}$ & CGE $^{2}$ & TKU $^{3}$ \\
\hline EFC & 1,000 & 330 & 32,5 & 147.666 & 330 & 32,5 & - & - & - & - \\
FMG & 1,000 & 250 & 42,0 & 107.260 & 250 & 42,0 & - & - & - & - \\
NEWM & 1,000 & 268 & 37,5 & 94.382 & 268 & 37,5 & - & - & - & - \\
EFVM & 0,837 & 252 & 27,5 & 91.917 & 247 & 27,5 & 109.768 & 5 & - & 17.851 \\
RTHA & 0,752 & 236 & 40,0 & 77.160 & 236 & 34,7 & 102.577 & - & 5,3 & 25.417 \\
MAUR & 0,413 & 210 & 30,0 & 11.686 & 80 & 11,3 & 28.315 & 130 & 18,7 & 16.628 \\
IOL & 0,406 & 68 & 32,5 & 10.491 & 68 & 10,2 & 25.830 & - & 22,3 & 15.339 \\
CART & 0,332 & 200 & 30,0 & 10.500 & 90 & 12,6 & 31.618 & 110 & 17,4 & 21.118 \\
QNSL & 0,322 & 265 & 36,0 & 7.608 & 67 & 9,4 & 23.596 & 198 & 26,6 & 15.988 \\
RHILL & 0,268 & 232 & 45,0 & 7.568 & 80 & 11,2 & 28.220 & 152 & 33,8 & 20.652 \\
RTRR & 0,118 & 167 & 40,0 & 8.570 & 167 & 25,3 & 72.383 & - & 14,7 & 63.812 \\
AML & 0,111 & 70 & 30,0 & 510 & 13 & 1,8 & 4.601 & 57 & 28,2 & 4.091 \\
\hline
\end{tabular}

Nota. Fonte: Elaborado pelos autores. Unidades de medida: ${ }^{1}$ quantidade de vagóes por trem; ${ }^{2}$ toneladas por eixo (ton/eixo); ${ }^{3}$ milhôes de toneladas por quilômetro (milhōes ton.km).

A Tabela 4 também apresenta o alvo e o incremento necessário na variável de saída TKU, para que as DMUs atinjam índice de eficiência igual a um. Observa-se nos resultados que nove DMUs precisam de ajustes no TKU. É proposto um aumento de $19 \%$ no TKU da ferrovia EFVM e de 33\% no TKU da ferrovia RTHA. As ferrovias RTRR, RHILL, QNSL, CART, AML, IOL e MAUR precisam aumentar mais de 140\% de seu TKU para se tornar eficientes.

Para a análise dos resultados foi utilizado o fluxo proposto na Figura 4, que ressalta os pontos que precisam ser analisados antes de uma tomada de decisão, considerando o aumento de variável de saída e/ou eliminação das folgas das variáveis de entrada.

Apesar de os resultados indicarem necessidade de incremento de TKU para as DMUs náo eficientes, é preciso avaliar se as empresas têm condiçóes e/ou interesse de investir para aumentar a produção e se as minas/pelotizadoras têm capacidade de expandir a produção. Também podem existir minas com a produçáo em crescimento, ou projetos em ramp up, e, assim, a ferrovia pode já possuir vagóes, locomotivas e capacidade de transporte, porém, como a mina não está produzindo em pleno potencial, a ferrovia opera abaixo da capacidade instalada.

Outra causa levantada pode ser a existência de minas em exaustáo de sua produçáo, tendo volumes decrescentes, levando a ferrovia a ter vagóes em excesso. Todavia, a redução da frota náo seria viável caso a empresa tenha projetos para reposição desse volume, o que levaria à utilização desses ativos no futuro. 


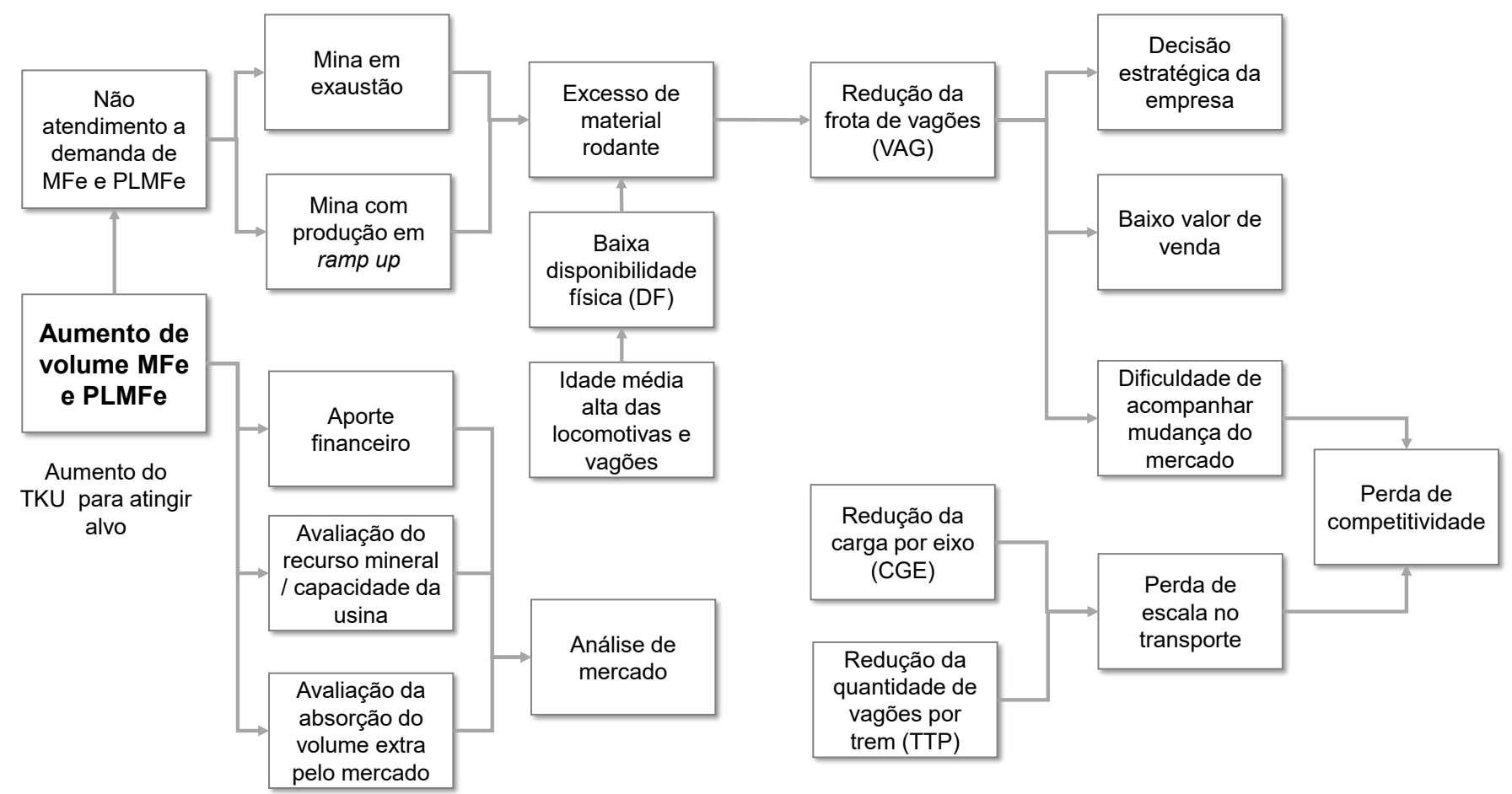

Figura 4. Fluxo para análise dos resultados do software Frontier Analyst.

A redução de vagôes pode deixar a empresa vulnerável em caso de mudança do mercado de MFe e PLMFe. Um desinvestimento na ferrovia poderia acarretar uma perda de competitividade, além do valor baixo que se conseguiria com a venda desses vagóes. Mas essa redução pode ser uma decisão estratégica, tomada pela alta administração das empresas.
A Tabela 5 apresenta um resumo do percentual de aumento do TKU, o volume de MFe/PLMFe que cada DMU movimentou (TUU) em 2016 e o valor necessário de aumento de produção para atingir o índice de eficiência igual a um. As análises a seguir foram realizadas tomando como base as Tabelas 1, 2 e 4.

Tabela 5. Resumo da análise das sugestóes sobre o aumento do volume movimentado.

\begin{tabular}{|c|c|c|c|c|}
\hline DMU & $\begin{array}{l}\text { Aumento do TKU } \\
(\%)\end{array}$ & Volume em $2016^{1}$ & $\begin{array}{l}\text { Volume necessário } \\
\text { para atingir } \\
\text { eficiência }^{1}\end{array}$ & Análise das sugestóes sobre capacidade produtiva \\
\hline EFC & - & 148 & - & Produção crescente do projeto $S 11 \mathrm{D}$ \\
\hline FMG & - & 173 & - & Sem planos de crescimento da produção \\
\hline NEWM & - & 222 & - & Possui projeto de expansão para $290 \mathrm{Mta}$ \\
\hline EFVM & $19 \%$ & 103 & 123 & Sem planos de crescimento de produção \\
\hline RTHA & $33 \%$ & 235 & 313 & Sem planos de crescimento de produção \\
\hline MAUR & $142 \%$ & 17 & 40 & Sem planos de crescimento de produção \\
\hline IOL & $146 \%$ & 27 & 66 & Sem planos de crescimento de produção \\
\hline CART & $201 \%$ & 25 & 76 & Sem planos de crescimento de produção \\
\hline QNSL & $210 \%$ & 18 & 56 & Sem planos de crescimento de produção \\
\hline RHILL & $273 \%$ & 22 & 82 & Produção crescente com estabilidade em 2018 de 55 Mta \\
\hline RTRR & $745 \%$ & 35 & 299 & Sem planos de crescimento de produção \\
\hline AML & $802 \%$ & 2 & 19 & Possui projeto de expansão para $15 \mathrm{Mta}$ \\
\hline
\end{tabular}

Nota. Fonte: Elaborado pelos autores. Unidade de medida: ${ }^{1}$ milhôes de toneladas. 
Na maioria dos casos, o aumento de TKU necessário para alcançar a eficiência dificilmente seria obtido, pois a maioria das empresas está mantendo estável sua produção de MFe/PLMFe, incentivadas pela incerteza do mercado e grandes oscilaçóes do preço do MFe. Por outro lado, em caso de mudança no cenário mundial e aumento da demanda, as empresas precisariam aumentar sua produçáo e adequar suas ferrovias para o escoamento dos produtos.

De fato, várias empresas não têm planos para crescer, mas podem a qualquer momento aumentar a produção em função do aumento da demanda global. No entanto, a ferrovia possui uma operaçáo pouco flexível e não absorve ajustes em um curto período. Como a alteração da frota de ativos é muito complexa, pois o valor residual de vagóes e locomotivas é ínfimo para venda, sendo vendidos quase como sucata, é extremamente improvável que sejam comprados numa eventual retomada da demanda mundial. Assim, entendemos que o foco da empresa é crescer e atender ao mercado e não ir definhando por não ter ativos que a permitam responder à demanda.

A EFVM possui uma malha bastante ramificada e é a única ferrovia de bitola métrica, o que implica em utilizaçáo de vagáo de menor porte. Por isso, a capacidade de transporte da EFVM é menor do que as outras ferrovias de MFe e PLMFe consideradas neste trabalho. Para que essa ferrovia se torne eficiente, o modelo CCR output sugere um aumento de 19\% em seu TKU, passando de 91.917 milhóes ton.km para 109.768 milhóes ton.km. Esse percentual representa um aumento de 103 Mta para 120 Mta. Apesar de ter capacidade produtiva, a Vale divulgou para o mercado que não faria investimentos no Sistema Sudeste, que é atendido pela ferrovia EFVM, concentrando os esforços na expansão da produção da mina de MFe S11D do Sistema Norte, que é atendida pela ferrovia EFC.

A EFC é a única ferrovia entre as DMUs estudadas que possui bitola de 1,60 m, tendo o maior trem, com 330 vagóes. Ela é considerada pelo método DEA como eficiente por default por possuir o maior valor de TKU da amostra e não demanda nenhum ajuste. A EFC possui as variáveis de entrada condizentes com o volume de MFe transportado. A Vale Norte apresenta uma produção crescente de MFe no longo prazo, oriundo do projeto S11D.

A NEWM é a única ferrovia australiana ativa da BHP após a paralisação da mina Yarrie em 2014, que era atendida pela ferrovia Goldsworthy. Ela possui bitola standard de 1,435 $\mathrm{m}$ e atende a quatro complexos de minas, transportando MFe. Essa ferrovia também foi considerada eficiente, dispensando ajustes em suas variáveis de entrada e saída. A BHP apresenta uma produçáo crescente de $\mathrm{MFe}$ no longo prazo e bom equilíbrio entre os inputs e o output, o que poderá mantê-la como uma ferrovia eficiente nos próximos anos.
A Rio Tinto possui dois corredores logísticos, compreendidos pelas ferrovias RTRR e RTHA, ambas de bitola standard. $\mathrm{O}$ resultado sugere um aumento expressivo da quantidade de TKU da ferrovia RTRR, passando de 8.570 milhōes ton.km para 72.383 milhóes ton.km. Já na ferrovia RTHA, a alteração é menor. O resultado sugere que o TKU seja aumentado de 77.146 milhóes ton.km para 102.577 milhōes ton.km, representando um acréscimo de 33\%. No atual cenário, o aumento do TKU não se mostra favorável porque a Rio Tinto apresenta em seu planejamento de longo prazo uma produçáo estável de MFe até 2025, tendo em vista que seus projetos são para suprir o volume perdido com a exaustão de algumas minas. No entanto, ela mantém uma quantidade de material rodante superior ao necessário porque possui outros projetos de expansão temporariamente suspensos, aguardando uma retomada crescente da demanda por MFe. Para a ferrovia RTRR, o aumento de TKU é muito alto, o que dificilmente seria atendido pela capacidade produtiva do Complexo Robe River. Uma avaliaçáo mais criteriosa se faz necessária para certificar que as variáveis de entrada estão superdimensionadas em relação ao volume previsto nos novos projetos.

A FMG é uma ferrovia exclusiva para MFe, com bitola standard e com 42 toneladas por eixo. É uma ferrovia nova, bem estruturada, com capacidade de via preparada para futuras expansóes. Seu trem tipo é o de maior capacidade da amostra, com 37.000 toneladas e com composiçáo de trem equiparada às outras ferrovias australianas. Foi considerada pelo modelo como eficiente, sem ajustes a serem feitos.

A RHILL é a mais recente ferrovia australiana de grande porte, que entrou em operação em 2015, com 45 toneladas por eixo, bitola standard e movimentaçáo de MFe na região de Pilbara. Seu índice de eficiência é 0,268 e demanda incremento no TKU, sendo sugerido um aumento de $273 \%$, indo de 8.570 milhóes ton.km para 28.220 milhóes ton.km. Essa ferrovia foi planejada para uma produção de MFe futura que ainda não foi atingida em sua plenitude até 2016. A ferrovia Roy Hill teve uma produçấo crescente de MFe até 2018, atingindo sua estabilidade com uma produçáo de $55 \mathrm{Mta}$. Por ser uma ferrovia nova e em expansão, torna-se interessante uma nova avaliação a partir de 2019 para verificar a melhoria em sua performance.

A ferrovia QNSL, da IOC, de bitola standard, faz o transporte de PLMFe e teve um índice de eficiência baixo igual a 0,322 . Os resultados apontam uma necessidade de aumento do TKU de 7.608 milhóes ton.km para 23.596 milhóes ton.km, o que representa um acréscimo de $210 \%$. A unidade produtiva de PLMFe da IOC não está preparada para esse aumento táo expressivo e seu planejamento mostra estabilidade na produção de longo prazo. A CART da Arcelor Mittal, de bitola standard, que transporta MFe e PLMFe, também teve índice de eficiência baixo, igual a 0,332. Para 
se tornar eficiente seria preciso aumentar o TKU em $201 \%$, saindo de 10.500 milhốes ton.km para 31.618 milhóes ton. $\mathrm{km}$. Em linhas gerais, é muito difícil que ferrovias do porte da CART e da QNSL tenham um aumento táo expressivo do volume transportado, por náo terem planos de crescimento nos próximos anos.

A ferrovia AML, da Arcelor Mittal, de bitola standard, transporta MFe na Libéria. É uma ferrovia de pequeno porte, com as operaçóes retomadas em 2015 e movimentação de 510 milhōes ton.km de MFe. Sua frota é pequena e seu trem é composto por apenas uma locomotiva e setenta vagóes, o que dificulta torná-la como referência para as demais ferrovias. A Arcelor Mittal da Libéria apresentou para o mercado o investimento em um projeto de expansão que elevará sua produção para $15 \mathrm{Mta}$. Esse crescimento atenderá parcialmente ao incremento de TKU na ferrovia AML, que demanda uma produção de 19 Mta para se tornar eficiente.

A ferrovia IOL possui bitola standard e movimenta MFe e PLMFe para exportação. Para se tornar eficiente, a IOL precisa fazer ajuste na variável TKU, com aumento de $146 \%$, passando de 10.491 milhóes ton.km para 25.830 milhóes ton. $\mathrm{km}$. A empresa demonstra em seu planejamento de longo prazo uma produçáo estável, o que dificulta o atendimento desse aumento de TKU.

A ferrovia MAUR, da SNIM, com índice de eficiência igual a 0,413 , precisa de um ajuste significativo na quantidade de TKU, indo de 11.686 milhóes ton.km para 28.315 milhóes ton.km, o que caracteriza um aumento de $142 \%$. A SNIM também apresentou um planejamento de longo prazo de estabilidade, inviabilizando um aumento tão expressivo.

De um modo geral, este estudo permite aos gestores conhecer quais são as adequações operacionais necessárias em relação à quantidade de vagóes por trem e carga por eixo, bem como a aquisiçáo de vagóes que permitirão seu crescimento para atendimento da demanda por MFe e PLMFe.

\section{CONCLUSÕES}

Este artigo propôs a utilização do método DEA CCR output para mensurar e comparar a eficiência das ferrovias especializadas em transporte de MFe e PLMFe que fazem parte do patrimônio das empresas de mineraçáo e usinas de pelotização e, portanto, não cobram frete para o transporte de MFe e PLMFe.

Foram definidas três variáveis de entrada por meio do método multicritério combinatório inicial, sendo elas: (a) a quantidade de vagóes em operação (VAG), (b) a carga por eixo do vagão (CGE) e (c) a quantidade de vagóes do trem tipo de maior predominância (TTP). A variável de saída foi a tonelada por quilômetro útil (TKU). Por último, foi utilizada a regressão Tobit como estratégia de validação do modelo DEA.

Pelo levantamento realizado das ferrovias que transportam MFe e PLMFe no cenário mundial do ano de 2016, descobriu-se que doze ferrovias são patrimônio das empresas mineradoras e/ou usinas de pelotizaçáo e não cobram frete das suas empresas proprietárias. Destas doze ferrovias, percebeu-se que três são consideradas como eficientes, sendo elas: (a) Estrada de Ferro Carajás (EFC), (b) Mount Newman (NEWM) e (c) Fortescue (FMG). As demais ferrovias precisam de ajustes para se tornar eficientes, sendo avaliadas proposiçóes em relaçáo ao mercado em que elas estão inseridas.

No modo geral, devido à proporcionalidade entre as variáveis de entrada e saída (i.e., retorno constante de escala), o modelo CCR output foi considerado um bom método para avaliar a eficiência das ferrovias especializadas em transporte de MFE e PLMFe, pois determinou a eficiência de cada DMU, sugerindo o aumento necessário do TKU para que as ferrovias atinjam o índice de eficiência igual a um e possíveis ajustes nas variáveis de entrada. No entanto, caso seja utilizado outro conjunto de variáveis que demonstre combinaçôes convexas (retorno crescente de escala) ou côncavas (retorno decrescente de escala), torna-se interessante a utilização do modelo BCC, considerando que os resultados estáo condicionados a um determinado conjunto de valores por se tratar de uma eficiência relativa.

Considerando que o mercado de MFe é muito dinâmico, as empresas poderão utilizar os resultados deste artigo para guiar melhorias futuras no caso de expansão da sua produção, tornando suas ferrovias mais eficientes ou se mantendo na fronteira de eficiência.

Por fim, este trabalho possui algumas limitações por restringir o escopo ao ano de 2016. Apresenta-se como oportunidade para estudos futuros a avaliação do quinto evento que alterou a dinâmica do mercado de MFe e PLMFe e desequilibrou a relação oferta-procura: o rompimento da barragem de rejeito de Brumadinho, ocorrido em 2019. Sugere-se também a aplicação da metodologia DEA para os portos, que sáo o elo seguinte da cadeia logística de MFe e PLMFe com destino ao cliente.

A continuidade deste e de outros trabalhos poderá proporcionar para as empresas de MFe e PLMFe indicativos de como aumentar sua eficiência nos elos da cadeia logística, reduzindo os custos e aumentando a margem de lucro.

\section{AGRADECIMENTOS}

Os autores agradecem ao Instituto Federal do Espírito Santo (IFES) pelo financiamento da tradução desse artigo ao idioma Inglês. 


\section{REFERÊNCIAS}

Asmild, M., Holvad, T., Hougaard, J. L., \& Kronborg, D. (2009). Railway reforms: Do they influence operating efficiency? Transportation, 36(5), 617-638. https://doi.org/10.1007/s11116-009-9216-x

Banker, R. D., Charnes, A., Cooper, W. W., Swarts, J., \& Thomas, D. (1989). An introduction to data envelopment analysis with some of its models and their uses. In P. A. Copley (Ed.), Research in governmental and nonprofit accounting (Vol. 5, pp. 125-163). Greenwich, CT: JAI Press.

Bogetoft, P., \& Otto, L. (2011). Benchmarking with DEA, SFA, and R (Vol. 157). New York: Springer-Verlag.

Caldas, M.A.F., Gabriele, P.D., Carvalhal, R. L., \& Ramos, T. G. (2012, September). A eficiência do transporte ferroviário de cargas: Uma análise do Brasil e dos Estados Unidos. Proceedings of Congreso Latino Ibero-Americano de Investigación Operativa e Simpósio Brasileiro de Pesquisa Operacional (CLAIO$S B P O)$, Rio de Janeiro, RJ, Brazil, 16. Retrieved from http://www.din.uem.br/sbpo/sbpo2012/pdf/arq0333.pdf

Cantos, P., Pastor, J. M., \& Serrano, L. (2012). Evaluating European railway deregulation using different approaches. Transport Policy, 24, 67-72. https://doi.org/10.1016/j.tranpol.2012.07.008

Charnes, A., Cooper, W. W., \& Rhodes, E. (1978). Measuring the efficiency of decision making units. European Journal of Operational Research, 2(6), 429-444. https://doi.org/10.1016/0377-2217(78)90138-8

Chernick M. R. (2008) Bootstrap methods: A guide for practitioners and researchers. Hoboken, NJ: Wiley.

Cinca, C. S., Molinero, C. M., \& Callén, Y. F. (2016). Input and output search in DEA: The case of financial institutions. In S.-N Hwang \& H.-S. Lee (Eds.), Handbook of operations analytics using data envelopment analysis (pp. 51-87). Boston: Springer.

Garside, M. (2020). Iron ore - statistics \& facts. Statista. Retrieved from https://www.statista.com/topics/1919/iron-ore/

Gujarati, D. N. (2000). Econometria básica. São Paulo, SP: Makron Books.

Kutlar, A., Kabasakal, A., \& Sarikaya, M. (2013). Determination of the efficiency of the world railway companies by method of DEA and comparison of their efficiency by Tobit analysis. Quality \& Quantity, 47(6), 3575-3602. https://doi.org/10.1007/s11135-012-9741-0

Lin, L. C., \& Tseng, C. C. (2007). Operational performance evaluation of major container ports in the Asia-Pacific region. Maritime Policy \& Management, 34(6), 535-551. https://doi.org/10.1080/03088830701695248

Marchetti, D., \& Wanke, P. (2017). Brazil's rail freight transport: Efficiency analysis using two-stage DEA and cluster-driven public policies. Socio-Economic Planning Sciences, 59, 2642. https://doi.org/10.1016/j.seps.2016.10.005

Mello, J. D. S., Gomes, E. G., Meza, L. A., \& Lins, M. E. (2004). Selección de variables para el incremento del poder de discriminación de los modelos DEA. Revista de la Escuela de Perfeccionamiento En Investigación Operativa, (24), 4052. Retrieved from https://www.alice.cnptia.embrapa.br/ bitstream/doc/17494/1/1805.pdf

Merkert, R., Smith, A. S. J., \& Nash, C. A. (2010). Benchmarking of train operating firms - a transaction cost efficiency analysis. Transportation Planning and Technology, 33(1), 35-53. https://doi.org/10.1080/03081060903429330

Miles, J., \& Shevlin, M. (2001). Applying regression and correlation: A guide for students and researchers. London: Sage.

Motta, G. D. S. (2017). Como escrever um bom artigo tecnológico? Revista de Administração Contemporânea, 21(5), 4-8. https:// doi.org/10.1590/1982-7849rac2017170258

Pereira, M. A., Rosa, F. S. da, \& Lunkes, R. J. (2015). Análise da eficiência ferroviária no Brasil nos anos entre 2009 a 2013. Transportes, 23(3), 56-63. https://doi.org/10.14295/transportes.v23i3.909

Reis, J. C., Sacramento, K. T., Mello, J. C. C. B. S. de, \& Meza, L. A. (2017). Avaliação de eficiência das ferrovias brasileiras: Uma aplicação do método multicritério para seleção de variáveis em DEA e representaçáo gráfica bidimensional. Revista Espacios, 38(14), 16-26. Retrieved from https:// www.revistaespacios.com/a17v38n14/17381416.html

Sharma, M. G., Debnath, R. M., Oloruntoba, R., \& Sharma, S. M. (2016). Benchmarking of rail transport service performance through DEA for Indian railways. The International Journal of Logistics Management, 27(3), 629-649. Retrieved from https://www.emerald.com/insight/content/doi/10.1108/ IJLM-08-2014-0122/full/html?fullSc=1

Senra, L. F. A. C., Nanci, L. C., Mello, J. C. C. B. S. de., \& Meza, L. A. (2007). Estudo sobre métodos de seleção de variáveis em DEA. Pesquisa Operacional, 27(2), 191-207. https://doi.org/10.1590/S0101-74382007000200001

Silva, F. G. F., Oliveira, R. L. M., \& Marinov, M. (2020). An analysis of the effects on rail operational efficiency due to a merger between Brazilian rail companies: The case of RUMO-ALL. Sustainability, 12(12), 4827. https://doi.org/10.3390/su12124827

Simar L. \& Wilson, P. W. (1998) Sensitivity analysis of efficiency scores: How to bootstrap in nonparametric frontier models. Management Science, 44(1), 49-61. Retrieved from http:// www.jstor.org/stable/2634426

Wanke, P., Chen, Z., Liu, W., Antunes, J. J., \& Azad, M. A. K. (2018). Investigating the drivers of railway performance: Evidence from selected Asian countries. Habitat International, 80, 49 69. https://doi.org/10.1016/j.habitatint.2018.08.004

Yu, M.-M. (2008). Assessing the technical efficiency, service effectiveness, and technical effectiveness of the world's railways through NDEA analysis. Transportation Research Part A: Policy and Practice, 42(10), 1283-1294. https://doi.org/10.1016/j.tra.2008.03.014

Zhou, H., \& Hu, H. (2017). Sustainability evaluation of railways in China using a two-stage network DEA model with undesirable outputs and shared resources. Sustainability, 9(1), 150. https://doi.org/10.3390/su9010150 


\section{Autoria}

\section{Renata Guimarães de Oliveira Fontan}

Universidade Federal do Espírito Santo, Programa de Pósgraduação em Engenharia Civil

Av. Fernando Ferrari, no 514, Goiabeiras, 29075-910, Vitória, ES, Brasil.

E-mail: regol.fontan@gmail.com

(1) https://orcid.org/0000-0002-2516-3514

\section{Rodrigo Alvarenga Rosa}

Universidade Federal do Espírito Santo, Programa de Pósgraduação em Engenharia Civil

Av. Fernando Ferrari, no 514, Goiabeiras, 29075-910, Vitória, ES, Brasil.

E-mail: rodrigoalvarengarosa@gmail.com

(1) https://orcid.org/0000-0003-0841-514X

\section{Adonai José Lacruz*}

Universidade Federal do Espírito Santo, Programa de Pósgraduação em Administração

Av. Fernando Ferrari, no 514, Goiabeiras, 29075-910, Vitória, ES, Brasil.

Instituto Federal do Espírito Santo

Rod. BR 101, Km 12, s/n, Universal, 29135-000, Viana, ES, Brasil.

E-mail: adonai.lacruz@ifes.edu.br

(1) https://orcid.org/0000-0003-1575-3788

* Autor Correspondente

\section{Financiamento}

Os autores relataram que não houve suporte financeiro para pesquisa deste artigo.

\section{Conflito de Interesses}

Os autores informaram que não há conflito de interesses.

\section{Verificação de Plágio}

A RAC mantém a prática de submeter todos os documentos aprovados para publicaçáo à verificaçáo de plágio, mediante o emprego de ferramentas específicas, e.g.: iThenticate.

\section{Contribuições dos Autores}

$1^{a}$ autora: conceituação (liderança); curadoria de dados (liderança); análise formal (liderança); metodologia (liderança); escrita - rascunho original (liderança); escrita revisão e edição (igual).

$2^{\circ}$ autor: conceituação (suporte); análise formal (suporte); metodologia (suporte); supervisáo (liderança); escrita rascunho original (suporte); escrita - revisão e ediçáo (igual). $3^{\circ}$ autor: metodologia (suporte); supervisão (suporte); escrita - rascunho original (suporte); escrita - revisão e edição (igual).

\section{Direitos Autorais}

A RAC detém os direitos autorais deste conteúdo.

\section{Método de Revisão por Pares}

Este conteúdo foi avaliado utilizando o processo de revisão por pares duplo-cego (double-blind peer-review). A divulgação das informaçóes dos pareceristas constantes na primeira página e do Relatório de Revisão por Pares (Peer Review Report) é feita somente após a conclusão do processo avaliativo, e com o consentimento voluntário dos respectivos pareceristas e autores.

\section{Disponibilidade dos Dados}

Todos os dados e materiais foram disponibilizados publicamente por meio da plataforma Harvard Dataverse e podem ser acessados em:

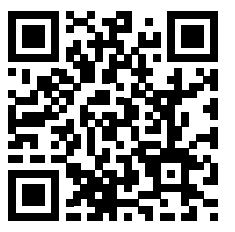

Renata Guimarães de Oliveira Fontan; Rodrigo de Alvarenga Rosa; Adonai Lacruz, 2021, "Replication Data for: The efficiency of railways specialized in transporting iron ore and pellets", Harvard Dataverse, V1. https://doi.org/10.7910/DVN/Y8CS9Q

A RAC incentiva o compartilhamento de dados mas, por observância a ditames éticos, não demanda a divulgação de qualquer meio de identificaçáo de sujeitos de pesquisa, preservando a privacidade dos sujeitos de pesquisa. A prática de open data é viabilizar a reproducibilidade de resultados, e assegurar a irrestrita transparência dos resultados da pesquisa publicada, sem que seja demandada a identidade de sujeitos de pesquisa. 